\title{
Deposition of diamond films on metal substrates ${ }^{\dagger}$
}

\author{
MANJU MALHOTRA, S C AGARWAL and SATYENDRA KUMAR \\ Department of Physics, Indian Institute of Technology, Kanpur 208016, India
}

\begin{abstract}
In this paper we report on the growth of polycrystalline diamond films on Mo, W, and $\mathrm{Ni}$ substrates using oxy-acetylene combustion flame technique. Effect of substrate temperature on the growth of diamond films has been studied in the temperature range $600-1100^{\circ} \mathrm{C}$. The deposits and their surface morphology has been characterized by X-ray diffraction and scanning electron microscopy (SEM). A short duration pretreatment of Mo substrates by outer zone of the oxy-acetylene flame at lower substrate temperatures, results in the improvement of quality and adherence of the films. Growth of diamond as well as other intermediate compounds depending on the nature of substrates and interface layers is discussed.
\end{abstract}

Keywords. Diamond films; oxy-acetylene flame; surface morphology; scanning electron microscopy.

\section{Introduction}

Interest in thin films of diamond and diamond like carbon (DLC) has been motivated due to their unusual combination of electrical, optical and thermal properties (Angus and Haymann 1988). Synthesis of these films by chemical vapour deposition (CVD) processes essentially requires activation of some hydrocarbon gases or vapours. The most widely used low pressure, low temperature techniques employ the decomposition of hydrocarbons either by using electron bombardment e.g. dc, rf, and microwave plasmas, or by using thermal energy e.g. hot filament CVD (Deshpandey and Bunshah 1989). A comparatively novel method of activating gas-phase carbon containing precursor molecules was proposed by Hirose and Kondo (1988) using a standard oxyacetylene combustion flame. This method has some unique advantages over other CVD techniques, e.g. higher growth rates, high crystal quality, and inexpensive and simple apparatus. Therefore, there has been a growing interest in depositing diamond films using oxy-acetylene flame.

Various authors have reported the combustion flame diamond synthesis on molybdenum (Ravi and Koch 1990; Hanssen et al 1991; Hirabayashi et al 1992; Marks et al 1993) and silicon substrates (Yarbrough et al 1989; Huang et al 1990; Snail et al 1990). Other substrates like copper, titanium and titanium nitride have also been used. In general, the choice of substrates for diamond deposition is made from two types of materials (Lee et al 1990). First type of materials are those which have thermal expansion coefficients or lattice constants close to that of diamond, e.g. Si or Ni. The second preferred substrate materials are those which form carbides having high surface free-energies relatively close to the surface free energy of diamond, e.g. Mo, Ta and W.

Apart from basic interest in understanding the nucleation and growth processes of diamond, synthesis of adherent diamond films on metal substrates is important for

\footnotetext{
${ }^{+}$Paper presented at the poster session of MRSI AGM VI, Kharagpur, 1995
} 


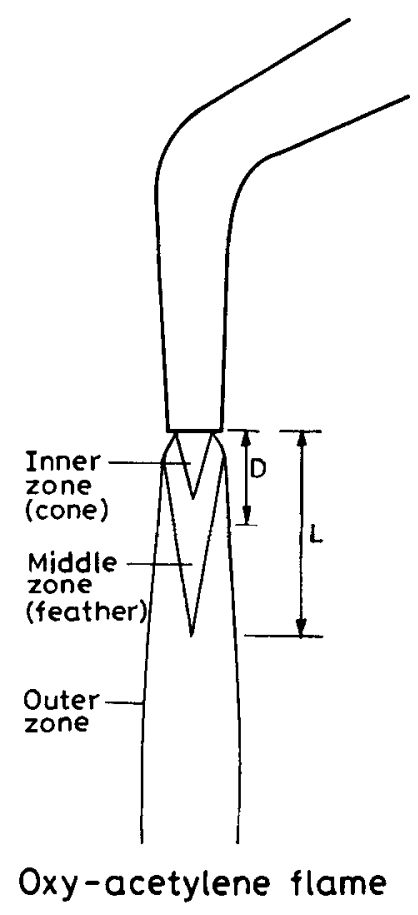

Figure 1. Oxy-acetylene flame structure.

various tribological and bio-medical applications. In this paper, we report the results of studies on oxy-acetylene flame deposition of diamond films on molybdenum, tungsten and nickel substrates.

\section{Experimental}

The substrates were ultrasonically cleaned in acetone and methanol and were then placed on a water cooled copper substrate holder. Substrate surfaces were not scratched. Substrate was self heated by heat transfer from the flame and its temperature was controlled by adjusting the flow rate of water to the substrate holder and was measured using a chromel-alumel thermocouple. Acetylene rich oxy-acetylene flame consists of three distinct zones viz. inner cone, acetylene feather (middle zone) and outer flame. Figure 1 shows its structure. This structure and relative sizes of the flame zones are dependent on flow rates of oxygen and acetylene gases as well as their flow ratios. In our experiments, the flow rates of gases were monitored and controlled using volume flowmeters and torch handle needle valves. The experiments performed for different flame structures and positions of the substrate in flame revealed that for acetylene rich flames, high quality diamond could be grown for a particular gas ratio which is directly related to the feather length $(L)$ and the placement of substrates in the specific region of the feather $(D)$ (see figure 1 ). $D$ and $L$ were measured using a millimeter scale made of quartz plate. The flame was set to optimum conditions as described in the next section. It should be emphasized that at a fixed substrate temperature reproducible samples were prepared by controlling $L$ and $D$ only. 
The deposition on various metal substrates were performed for deposition times of 10-30 min. Diamonds could be grown only in the middle zone (acetylene feather) of the oxy-acetylene flame (figure 1). Crystalline diamond films were obtained for $L$ between 25 and $35 \mathrm{~mm}$ and $\mathrm{D}$ from 7 to $15 \mathrm{~mm}$.

The identification of crystalline planes of diamond and the co-deposits in our samples was done by using an X-ray diffractometer (Siefert Isodebueflex 2002). SEM studies were performed to characterize surface morphology and determine particle density and particle size in the deposited films (scanning electron microscope-JEOL JSM-840 A).

\section{Results and discussion}

\subsection{Diamond growth on molybdenum}

Diamond films could be deposited on Mo substrates at the gas flow rates of about 1 slpm and $\mathrm{O}_{2} / \mathrm{C}_{2} \mathrm{H}_{2}$ flow ratio of about 0.9 which correspond to $L$ of about $30 \pm 1 \mathrm{~mm}$. The value of $D$ was found to be optimum at $12 \mathrm{~mm}$. At smaller $D$, deposition of accumulated ball-like structures along with high non-diamond carbon or soot was obtained. A decrease in growth rate was observed at larger $D$ values. Once the flame is set to optimum conditions, the uniformity, grain size and crystalline orientation are achieved by appropriate heat transfer on the substrates by the reactive flow of the hydrocarbon species and by simultaneous cooling of the substrates.

Figure 2 shows the $\mathrm{X}$-ray diffraction spectra measured on films deposited using $\mathrm{O}_{2} / \mathrm{C}_{2} \mathrm{H}_{2}$ flow ratio of 0.94 at three typical substrate temperatures $(660,850$ and $1060^{\circ} \mathrm{C}$ ). The optimum substrate temperature for diamond film deposition on Mo under these flame conditions is found to be $850 \pm 50^{\circ} \mathrm{C}$. The XRD spectrum of a film deposited for $10 \mathrm{~min}$ on Mo substrate by acetylene feather at this temperature is shown in figure $2 b$. This clearly shows four crystalline planes of diamond viz(111), (220), (311) and (400). The interplaner spacings $(d)$ obtained from the XRD pattern are consistent with those of the cubic diamond crystal (ASTM card 6-0676). The lattice parameter obtained on indexing the pattern was $3.572 \mathrm{~A}$, which is quite close to that of the natural diamond (3.567 A). An increase in lattice parameter indicates the synthesized polycrystalline diamond film in a state of tensile stress. Other peaks related to carbides and oxides of Mo are also seen (figure 2b).

Increasing the substrate temperature leads to the formation of graphite (figure 2a). XRD spectrum of a sample prepared at $1060^{\circ} \mathrm{C}$ (figure 2a) indicates that the film is basically composed of the graphite phase with no diamond peaks present. On the other hand, no crystalline deposits (graphite or diamond) is obtained at lower temperatures (figure 2c).

These observations are in general agreement with the results of Hanssen et al (1991), but are in contrast to those of Marks et al (1993) who reported the diamond growth on Mo at a temperature of $1250^{\circ} \mathrm{C}$ using a turbulent flame. It should be noted that the presence of chemical species in the flame is a function of position (Yalamanchi and Harshvardhan 1990). Preferential growth of graphite at high substrate temperatures may be attributed to atomic hydrogen which plays a paramount role in diamond vs graphite deposition in CVD processes also (Spear and Frenklach 1994). At high substrate temperatures (above $950^{\circ} \mathrm{C}$ ), hydrogen desorption from the diamond surface takes place (Pate 1986). 


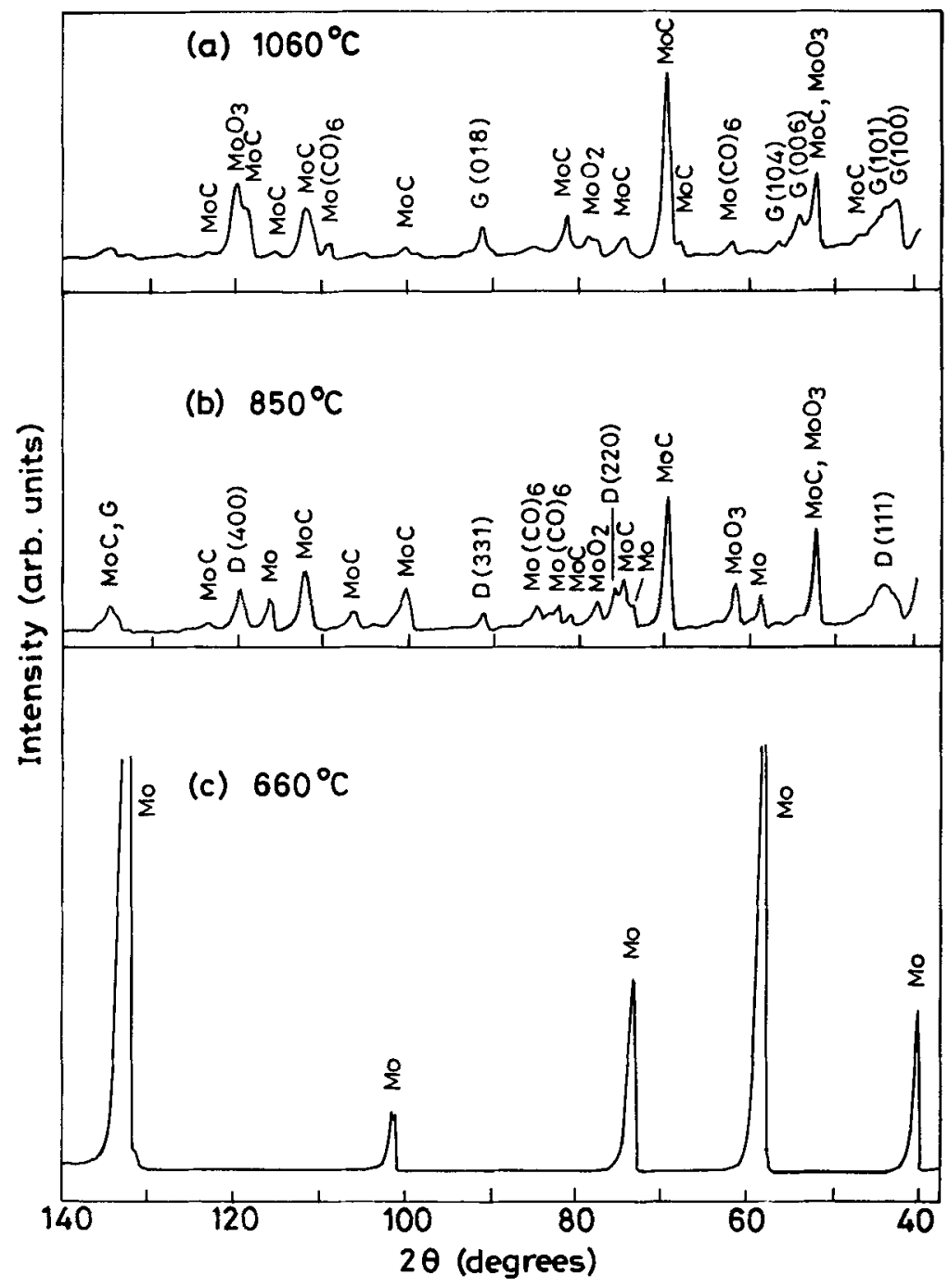

Figure 2. XRD spectra of samples prepared at substrate temperature of (a) $1060^{\circ} \mathrm{C}$, (b) $850^{\circ} \mathrm{C}$ and (c) $660^{\circ} \mathrm{C}$.

As the short residence time of hydrogen on the surface is not enough to stabilize, the surface hybridization and reconstruction of $s p^{3}$ hybridized carbon sites into $s p^{2}$ graphitic phase takes place. On the other hand, if the temperature is too low, the reduced mobility of carbonaceous species on substrate surface prevents crystallization which explains the absence of graphite or diamond peaks in the XRD spectrum of a sample prepared at $660^{\circ} \mathrm{C}$ (figure $2 \mathrm{c}$ ). In addition, oxidation and thermal decomposition of deposits may also play a crucial role in determining the formation of various polytypes of carbon and their growth rates (Bhargava et al 1995).

SEM micrographs of the sample corresponding to figure $2 b$ are shown in figure 3 . It shows the formation of individual particles distributed uniformly over the surface with a nucleation density $N$ of the order of $10^{5}$ particles $/ \mathrm{cm}^{2}$ (figure 3a). The morphology of the deposits is seen to consist of round shaped grains (figure $3 b$ ) having linear dimensions 

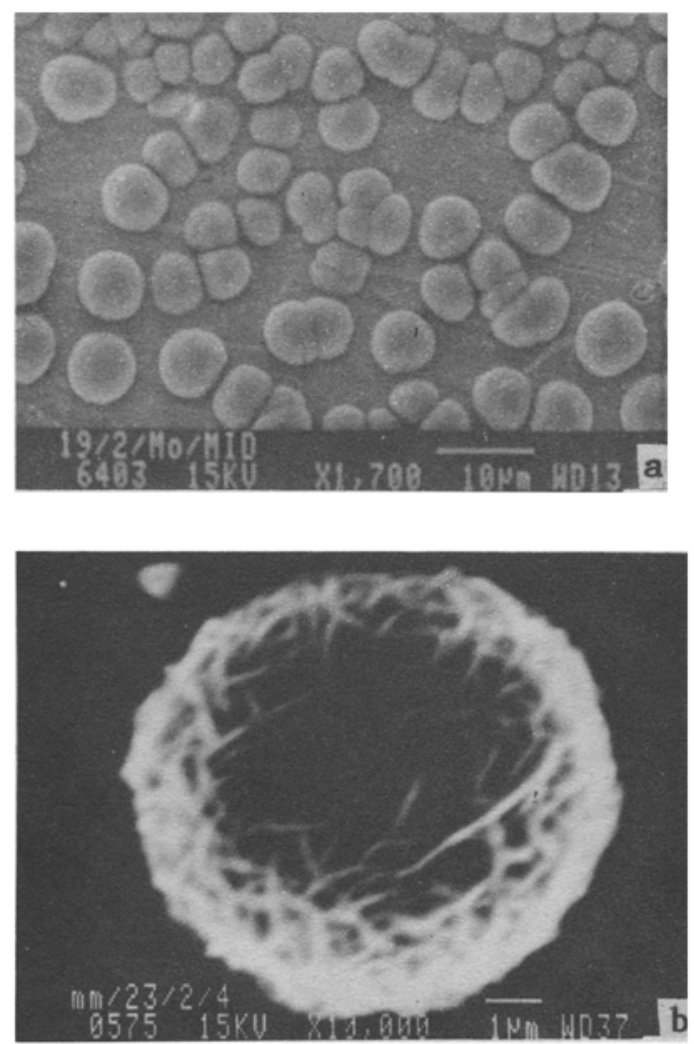

Figure 3. SEM photographs of diamond film grown on untreated Mo for $10 \mathrm{~min}$.

of about $10 \mu \mathrm{m}$ and a number of crystallites which tend to grow as faceted particles. The variation in the particle size as well as density was observed across the radial distance from the centre of the combustion flame which may be caused by the variation in the substrate temperature as well as the flame constituents. This is one of the inherent drawbacks of this deposition technique (Snail et al 1990; Hanssen et al 1991).

\subsection{Effect of pretreatment on molybdenum}

In order to get uniform films on various substrates a surface pretreatment using the outer zone of oxy-acetylene flame was tried. The substrate surface was exposed to the outer flame for different time-spans, immediately before the diamond synthesis using the middle flame. For this purpose, the same flame (fixed $L$ ) was utilized at larger $D$ values $(D>L$, typically $D \simeq 50-60 \mathrm{~mm})$ and lower substrate temperatures $\left(300-350^{\circ} \mathrm{C}\right)$. Deposition of diamond films was immediately followed by lowering the oxy-acetylene torch to adjust the $D$ value to $\simeq 12 \mathrm{~mm}$ and a substrate temperature of $850^{\circ} \mathrm{C}$. The XRD pattern of a sample deposited for $10 \mathrm{~min}$ after a $1 \mathrm{~min}$ pretreatment is shown in figure 4 . The formation of diamond marked $D$ (peaks 1,8,12 and 18) can be seen. In addition, peaks due to graphite (21 and 22), Mo (3,6 and 14) and compounds of Mo namely molybdenum-carbides $(2,5,7,9,10,13,15,19,22)$, oxides $(2,9,13,20)$ and oxy-carbides 


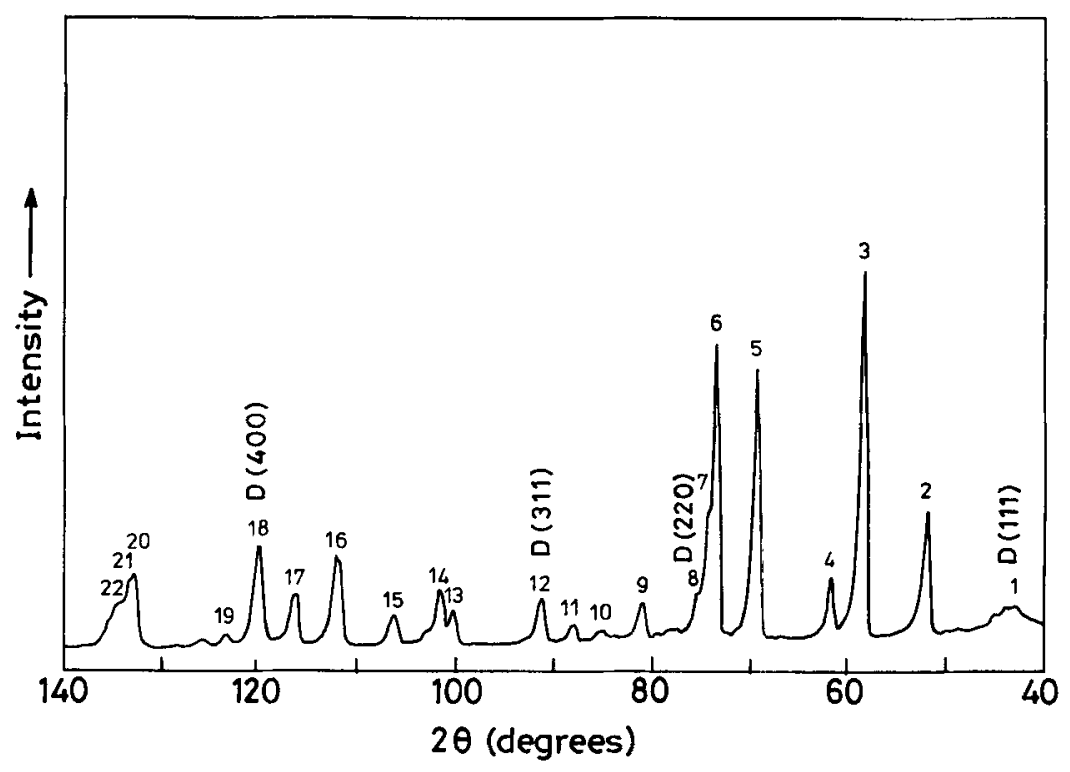

Figure 4. XRD spectrum of a diamond film deposited on Mo for $10 \mathrm{~min}$ with pretreatment for $1 \mathrm{~min}$.
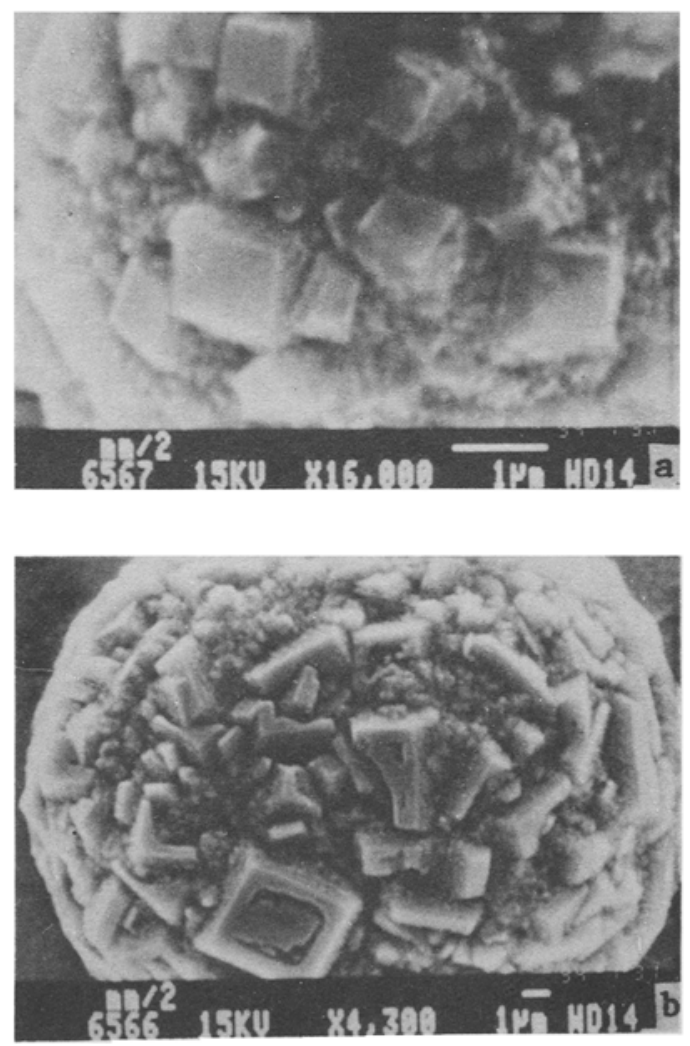

Figure 5. Surface morphology of the film corresponding to figure 4 . 
$(4,11,16)$ are also seen. Diamond $(400)$ peak is greater relative to other diamond peaks in the presence of interfacial layer resulting in the growth of square faceted flat diamond crystallites.

This flattening of crystallites is seen clearly in the SEM pictures (see figure 5) in which a number of diamond crystallites are connected with each other forming clusters of size ranging from 20 to $25 \mu \mathrm{m}$. For samples prepared without pretreatment (figure 3 ), the deposits consist of unconnected individual grains. This indicates that the interfacial layer formed during pretreatment facilitates in the coalescence of nearby grains across the surface and thus helps in the formation of clusters of faceted particles.

Effect of outer zone pretreatment time on the nucleation density is shown in figure 6 . Pretreatment time was varied from $30 \mathrm{sec}$ to $3 \mathrm{~min}$ keeping the subsequent diamond deposition time fixed at $10 \mathrm{~min}$. Formation of this interfacial layer for $1 \mathrm{~min}$ gave the maximum surface coverage with a particle density of $\simeq 8 \times 10^{4} / \mathrm{cm}^{2}$. At lower pretreatment time no change was observed in the diamond growth as compared to no pretreatment conditions. This may be because the self heating of the substrates takes some time to reach the desired temperature of about $350^{\circ} \mathrm{C}$. Increasing the pretreatment time to $3 \mathrm{~min}$ leads to decrease in particle density to $\simeq 4 \times 10^{3}$ particles $/ \mathrm{cm}^{2}$.

Similar results of lateral growth of diamond on Mo by sideways propagation of ledges formed on (100) diamond surfaces by oxidation has been observed by Ravi and Joshi (1991) at higher substrate temperatures. Our results compare favourably with those of Abe et al (1993) who obtained a particle density of $\simeq 3 \times 10^{4} / \mathrm{cm}^{2}$ after a similar preoxidation of the substrates at $1050 \mathrm{C}$ for $20 \mathrm{~min}$. The faceting of diamond crystallites on Mo oxides may be due to the suppression of graphite (Abe et al 1993) and lateral growth of diamond (Ravi and Joshi 1991). Further, we observed improvement in the adhesion of diamond films on pretreated substrates.

\subsection{Diamond growth on $\mathrm{W}$ and $\mathrm{Ni}$}

Studies on the growth of diamond on $\mathrm{W}$ and Ni substrates were also carried out. An XRD spectrum shown in figure 7 is taken on a sample prepared on tungsten using acetylene feather length of $L \simeq 25 \mathrm{~mm}$ and substrate temperature of $800^{\circ} \mathrm{C}$ without any pretreatment. The presence of reflection peaks from tungsten carbide and diamond exhibits the formation of carbide in the initial stages of deposition and subsequent growth of diamond. The corresponding SEM micrographs (figures 8a, b) show growth of diamond crystallites of about $4 \mu \mathrm{m}$ size with a density of $\simeq 2 \times 10^{5} / \mathrm{cm}^{2}$ in deposition run of $20 \mathrm{~min}$. Films grown at other substrate temperatures did not show diamond formation. Moreover, there were no tungsten carbide peaks in the X-ray diffraction at these temperatures. This leads to the speculation that the formation of carbides is an important step in nucleation of diamond on W substrates. Similar results were obtained by Akatsuka and Shimura (1991) and Williams et al (1991) using other deposition techniques. Perry and Somorjai (1994) studied the interfacial layer formed during growth of CVD diamond films on metal substrates including Ti, W, Mo and $\mathrm{Cu}$. Their results show the presence of carbides and oxides of the native metals at the interface. Carbides may induce carbon atoms to form critical nuclei rapidly enough before they re-evaporate during deposition.

Nickel being lattice matched to diamond attracts special attention as a substrate material (Belton and Schmieg 1989). However, an intermediate graphitic layer is 

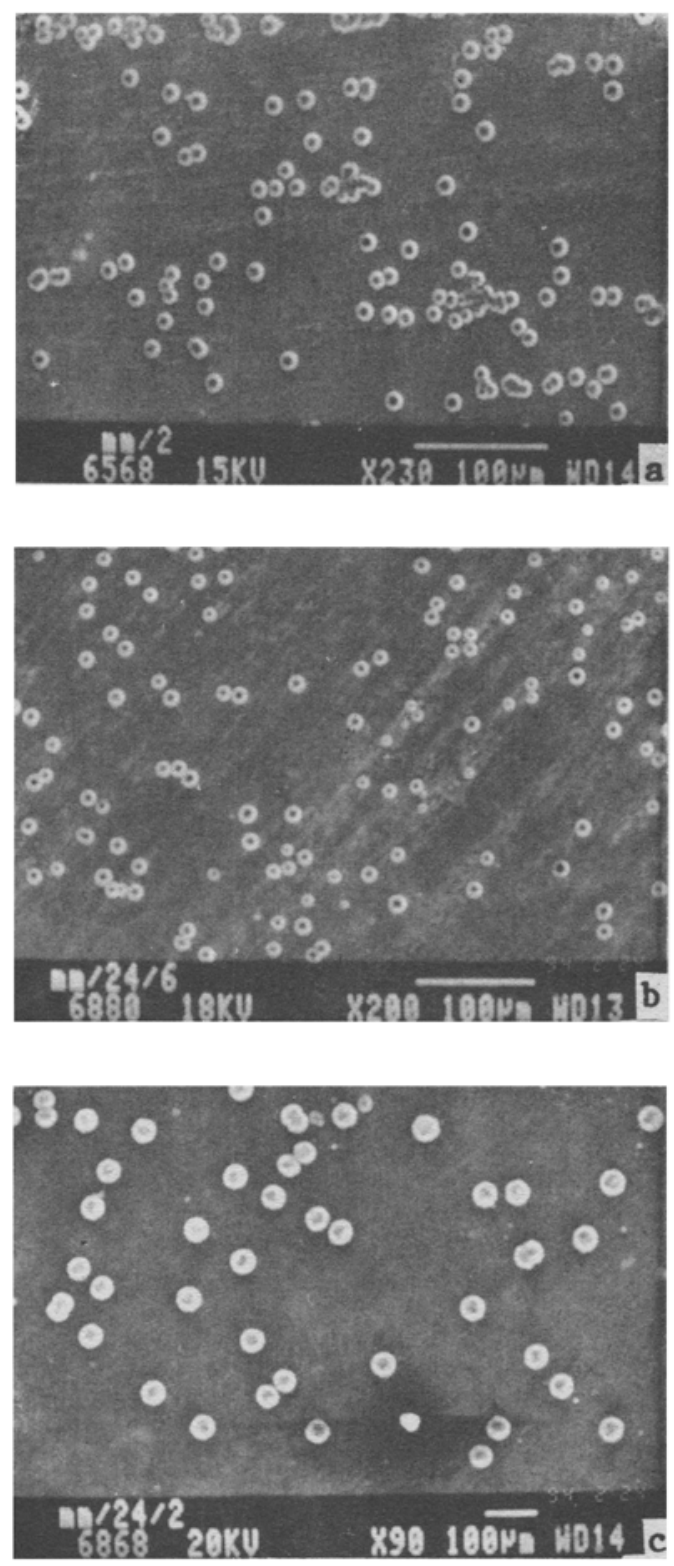

Figure 6. SEM pictures showing the particle density of film deposited for $10 \mathrm{~min}$ on Mo pretreated by outer flame for (a) $1 \mathrm{~min}$, (b) $2 \mathrm{~min}$ and (c) $3 \mathrm{~min}$.

usually present while depositing diamond on Ni. Godbole et al (1995) overcame this problem by using AlN interfacial layer. A seeding and multistep deposition process is also reported (Zhu et al 1993) which shows the formation of certain types of nickelcarbon-hydrogen intermediate states. However, no reports of diamond deposition on $\mathrm{Ni}$ substrates by oxy-acetylene flame method are available. We have attempted to grow diamond films on $\mathrm{Ni}$ using this method. 


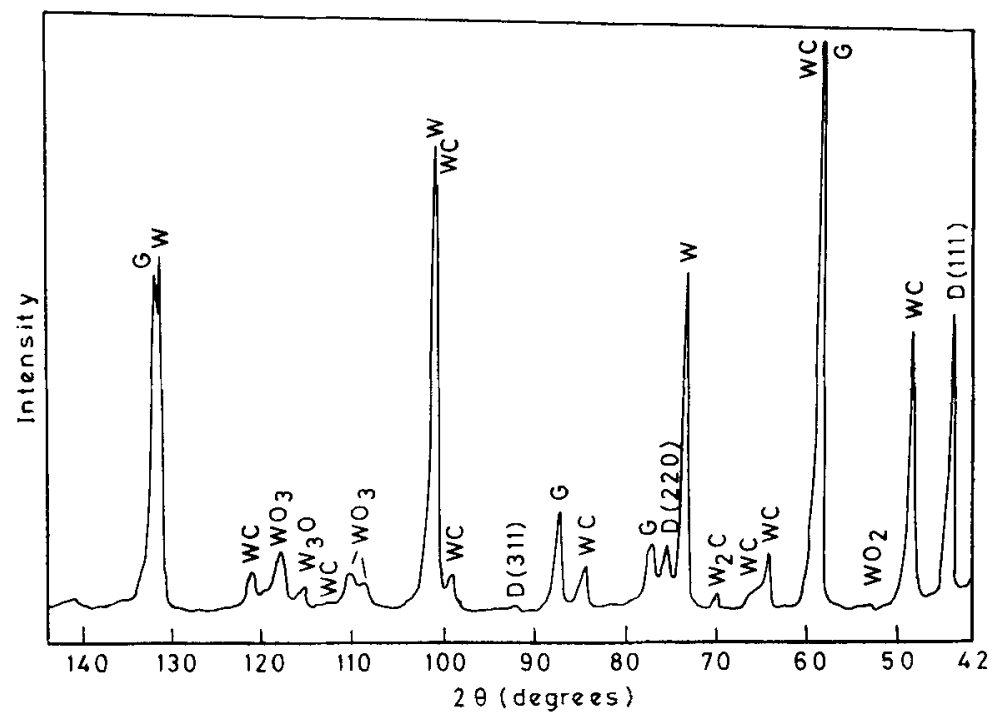

Figure 7. XRD spectrum of a diamond film on $\mathrm{W}$ at substrate temperature of $800^{\circ} \mathrm{C}$.
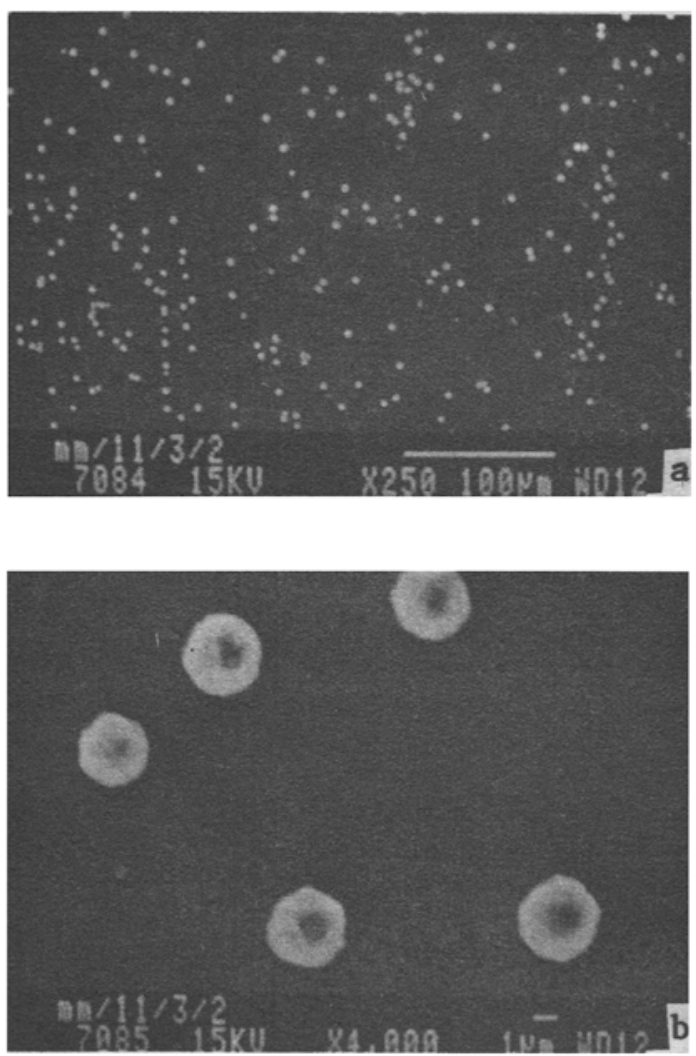

Figure 8. SEM photographs showing diamond particles on $\mathbf{W}$. 

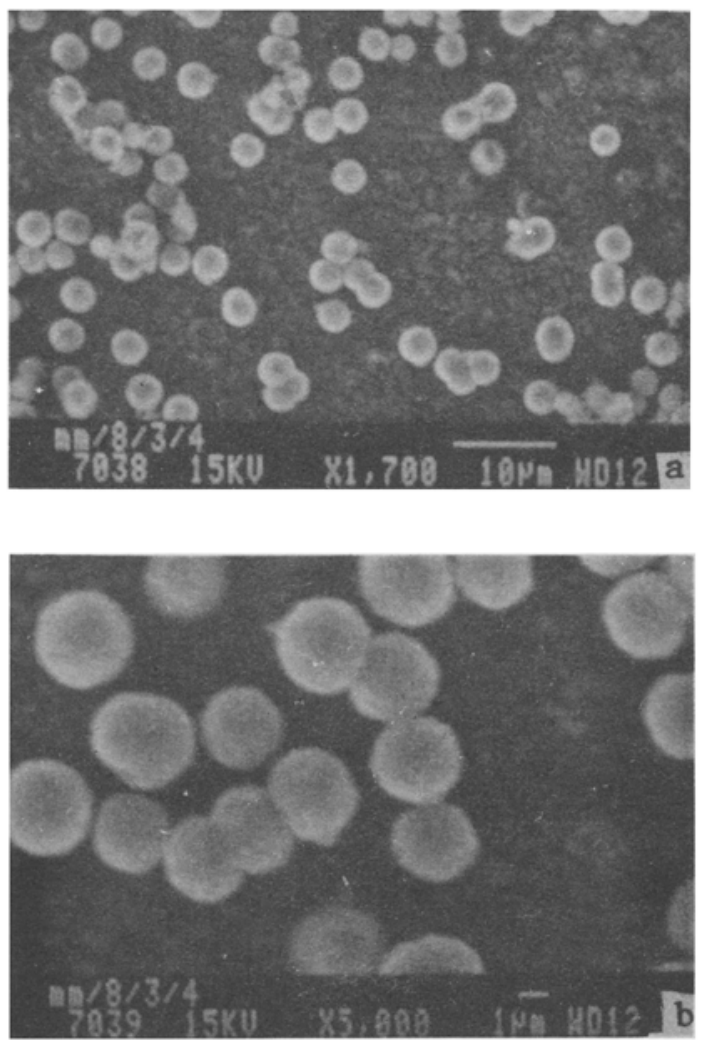

Figure 9. SEM photographs showing diamond particles on Ni.

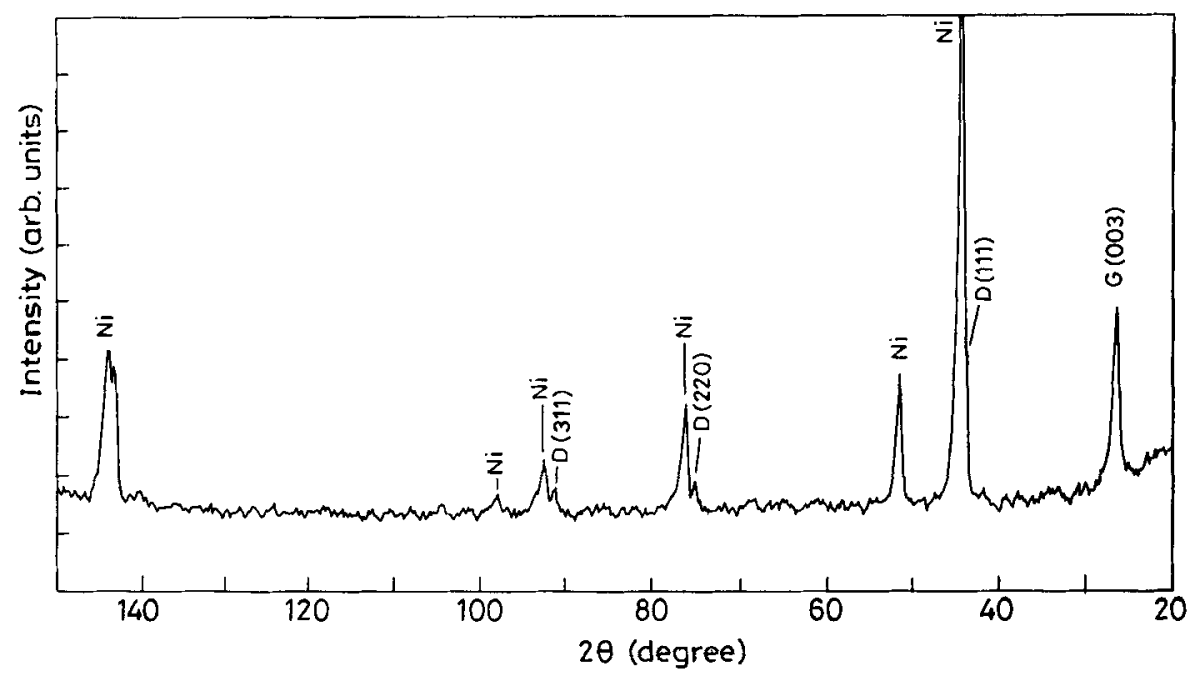

Figure 10. XRD spectrum of a diamond film on Ni at substrate temperature of $650^{\circ} \mathrm{C}$.

SEM micrograph of a sample (figure 9) prepared on nickel substrate using feather length of $L \simeq 15 \mathrm{~mm}$ and substrate temperature of $650^{\circ} \mathrm{C}$, shows the growth of $4-5 \mu \mathrm{m}$ size diamond crystallites with a density of $\simeq 3 \times 10^{6} / \mathrm{cm}^{2}$ in a deposition run of $20 \mathrm{~min}$. 
$X$-ray diffraction measurements on the same sample (figure 10) indicated the formation of diamond and graphite in addition to traces of oxides of nickel. The presence of diamond peaks in X-ray diffraction spectrum shows the possibility of using oxyacetylene flame method to grow diamond on Ni substrates. Further optimization of flame parameters and substrate temperature etc are required to obtain good quality diamond films.

Pretreatment of the W and Ni substrates using outer zone of the oxy-acetylene flame, under similar conditions as on Mo were carried out. However, no significant changes in the growth behaviour, i.e. lateral growth by formation of faceted diamond, were obtained. This difference in case of $\mathrm{W}$ and $\mathrm{Ni}$ as compared to that of Mo could be ascribed to the nature and availability of surface oxides formed during treatment by the outer zone of the flame at low substrate temperatures $\left(\sim 350^{\circ} \mathrm{C}\right)$.

\section{Conclusions}

Diamond films with predominantly (100) facets are deposited on Mo substrates in a stationary, single nozzle oxy-acetylene flame. Results of deposition runs using different parts of the flame as well as using different gas ratios to obtain different flame structures suggest that diamond is deposited via the transport of hydrocarbon species produced in the acetylene feather of the flame for the gas flow ratios close to unity. Formation of an interfacial layer on molybdenum by outer zone of the flame suggests that this layer improves quality via growth of (100) faceted crystals of diamond. In order to understand the influence of this layer on nucleation behaviour and adhesion of diamond crystals, more extensive structural investigations are in progress.

Our results on Mo, W and Ni substrates and nature of intermediate compounds formed suggest that the formation of a carbide layer is not necessary for diamond growth in all cases. Key to the diamond nucleation on various metal substrates is the generation of a diffusion barrier preventing carbon diffusion into the substrate bulk, either by carbide formation or by surface carbon saturation.

These studies also show that nucleation and growth of diamond on tungsten virtually takes place on its carbide. This suggests that it would be possible to apply oxy-acetylene flame CVD process for diamond deposition on WC-tool inserts, widely used for tribological applications. For such industrial applications, flame deposition technique needs to be perfected for larger area deposition. This might possibly be achieved by utilizing a multi nozzle (Tzeng et al 1990) and scanning (Murakawa et al 1990) flame.

\section{Acknowledgements}

We acknowledge Uma Shanker and P K Pal of ACMS, IIT Kanpur for X-ray diffraction and SEM measurements, respectively. Thanks are due to $M N$ Islam for experimental help. Technical support of Ram Bilas is greatly appreciated.

\section{References}

Abe T, Suemitsu M, Miyamato N and Sato N 1993 J. Appl. Phys. 73971

Akatsuka F and Shimura F 1991 Application of diamond films and related materials, (eds) Y Tzeng, M Yoshikawa, M Murakawa and A Feldman (Amsterdam: Elsevier) p. 379 
Angus J C and Haymann C C 1988 Science 241913

Belton D N and Schmieg S J 1989 J. Appl. Phys. 664223

Bhargava S, Bist H D, Sahli S, Aslam M and Tripathi H B 1995 Appl. Phys. Lett. 671706

Deshpandey C V and Bunshah R F 1989 J. Vac. Sci. Tech. 72294

Godbole V P, Jagannadham K and Narayan J 1995 Appl. Phys. Lett. 671332

Hanssen L M, Snail K A, Warrington W A, Butler J E, Kellog S and Oakes D B 1991 Thin Solid Films 196271

Hirabayashi K, Amanuma S and Hirose Y 1992 Appl. Phys. Lett. 60574

Hirose Y and Kondo N 1988 Extended abstracts, 35th Jpn. appl. phys. spring meet, (Tokyo: The Japan Society of Applied Physics) p 434

Huang J, Zhang K, Kwak B S, Erbit A and Feng Z C 1990 J. Mater. Res. 52334

Lee Y H, Bachmann K J, Glass J T, Lee Grice Y M and Nemanich R J 1990 Appl. Phys. Lett. 571916

Marks C M, Burris H R, Grun J and Snail K A 1993 J. Appl. Phys. 73755

Murakawa M, Takeuchi S and Hirose Y 1990 Surf. Coat. Tech. 43/44 22

Pate B B 1986 Surf. Sci. 16583

Perry S S and Somorjai G A 1994 J. Vac. Sci. Tech. 121513

Ravi K V and Joshi A 1991 Appl. Phys. Letr. 58246

Ravi K V and Koch C A 1990 Appl. Phys. Lett. 57348

Snail K A, Oakes D B, Butler J E and Hanssen L M 1990 New diamond science and technology, (eds)

R Messier, J T Glass, J E Butler and R Roy (Pittsburgh, Pennsylvania: MRS) p. 503

Spear K E and Frenklach M 1994 Pure \& Appl. Chem. 661773

Tzeng Y, Phillips R, Cutshaw C and Srivynunon T 1990 New diamond science and technology (eds) R Messier,

J T Glass, J E Butler and R Roy (Pittsburgh, Pennsylvania: MRS) p. 523

Williams B E, Stoner B R, Asbury D A and Glass J T 1991 Diamond and diamond-like films and coatings (eds)

R E Clausing, L L Hortan, J C Angus and P Koidl (New York: Plenum Press) p. 737

Yalamanchi R S and Harshvardhan K S 1990 J. Appl. Phys. 685941

Yarbrough W A, Stewart M A and Cooper J A Jr 1989 Surf. \& coat. tech. 39/40 241

Zhu W, Yang P C and Glass J T 1993 Appl. Phys. Lett. 631640 